REGULAR ARTICLE

\title{
DOES HUMAN CAPITAL EXPLAIN FOOD INSECURITY STATUS OF RURAL HOUSEHOLDS OR VICE-VERSA?
}

\author{
Oluwakemi OBAYELU * (iD), Abimbola ADEPOJU (iD, Olukemi OMIRIN
}

\author{
Address: \\ University of Ibadan, Faculty of Agriculture, Department of Agricultural Economics, University of Ibadan, Nigeria \\ * Corresponding author's e-mail: jkemmyade @ yahoo.co.uk
}

\begin{abstract}
Food security and human development are intricately linked and no meaningful progress can be sustained without an affiliated progress on the other. Fighting food insecurity therefore requires an increase in the level of human capital. However, food insecurity and low level of human capital development are major challenges among the rural milieu in Nigeria. The effect of human capital on food insecurity status among rural households in Nigeria was therefore investigated in this study. Principal Component Analysis was used to generate human capital index which comprised age, age squared, education, number of inactive days and body mass index of the household head. Household heads that had medium level of human capital were food secure. Human capital index, household size, being a male-headed household, membership of association, land ownership and access to extension significantly reduced food insecurity. Although human capital index had a negative effect on food insecurity, there was no bicausality between them.
\end{abstract}

Keywords: Dietary diversity, human capital, bicausality, rural Nigeria

JEL: J24, I10

\section{INTRODUCTION}

Food is the most basic need of man and it provides nutrients, which are indispensable for the maintenance of good health, improvement of wellbeing, and labour productivity (Ogundari, 2017). Africa remains the region with the highest proportion of undernourished people in the population, at 29 percent, compared with a 17 percent average for developing countries (United Nations, 2009). In addition to chronic hunger and malnutrition, parts of the continent have been hit by sudden crises that create bouts of acute hunger (Wiggins and Keats, 2009). Food insecurity in sub-Saharan Africa is characterized by widespread and chronic hunger and malnutrition as well as recurrent and acute food crises. Sub-Saharan Africa is the most vulnerable region to food insecurity and Nigeria is one of the food deficit countries in sub Saharan Africa (F.A.O, 2015). However, ensuring food security in developing countries is a global goal (Offiong et al., 2016).

Food insecurity has been on the increase in most rural areas in Nigeria (Oni et al., 2011) and over 70 percent of the food insecure population in Africa lives in rural areas (Mwaniki, 2005). Recent volatility in international food prices, combined with balance of payment difficulties in some food deficit countries, resulted in several countries needing to secure additional food supply through food aid (Pedro et al. 2011). Food insecurity is measured as a household-level concept that refers to uncertain, insufficient, or unacceptable availability, access or utilization of food (Habicht et al., 2004). The African continent is the only region of the developing world to continue experiencing difficulties after the green revolution of the 1970s and 1980s (Sanchez and Sachs, 2004). Since the 1970s, food production per capita on the continent has been declining by about $20 \%$ (Ouedraogo, 2005). To reverse the decline of the agricultural sector on the continent, the assembly of heads of state and Government of the African Union ratified the declaration on agriculture and food security in Maputo in July 2003 (Conceição et al., 2011).

Human capital has been identified as a means of increasing productivity and agricultural income thereby reducing food insecurity (Schultz, 1961). It has been argued that food security and human development are intricately linked, and that meaningful progress on one cannot be sustained without concomitant progress on the other (Conceição et al., 2011). Human capital is built on four pillars viz: education, health and wellness, nutrition and skills (work force and employment) (Fafchamps and Quisumbing, 1999). Low or lack of education reduces opportunities available to households to undertake high income paid jobs. It restricts households to low income jobs (menial jobs) and this makes the household unable to acquire resources to purchase food for consumption thereby increasing the level of food insecurity among the households. Poor health result from lack of health facilities which are a constant feature of most rural areas in Nigeria. Possession of skill increases the opportunity available to household members as it increases their ability to engage in multiple jobs to acquire more income to feed their household members. Hence lack of skill makes people in the households unqualified for certain jobs which invariably reduce income available to the 
household members' thereby increasing food insecurity among the households. The problem of food insecurity especially during the hungry period among rural households in Nigeria is long standing (Obamiro et al., 2005). Thus, since about half of Nigeria's living in rural areas (World Bank 2018), an examination of the factors associated with food insecurity status of rural households in Nigeria is pertinent if progress is to be made towards achieving the second Sustainable Development Goal of zero hunger.

A lot of work has been done on rural household food insecurity in rural Nigeria (Ajani, 2010; Ayantoye et al., 2011; Adepoju and Adejare, 2013; Agbola, 2014; Ogundari, 2017), however there is a paucity of information on its relationship with human capital. This study adds to existing literature by investigating the bicausal effect of human capital on food insecurity status of rural households in Nigeria. Achieving food security is a core Sustainable Development Goal (SDG) and achieving improved level of human capital is also a component of the SDG. This study investigated how human capital affects food security status of rural households.

\section{DATA AND METHODS}

The study made use of the general household survey 2015 data set carried out by the National Bureau of statistics. The information used for this study are the socioeconomic characteristics such as age (years), gender, education (years of formal education), household size, marital status, occupation, per capita income, access to extension, access to credit, farm size, land ownership, geo political zones, membership of association. The study made use of a two-stage sampling design for the survey. In the first stage, Enumeration Areas (EAs) were selected based on probability proportional to size (PPAs) in each state and Federal Capital Territory and total household in those EAs. The second stage involved a selection of households.

The food security status was measured using dietary diversity score into low and high diversity which afterwards was profiled across household socio-economic characteristics. The various food consumed by the households were grouped into twelve categories. The twelve food groups included in the HDDS were: (1) Cereals (maize, rice, millet and sorghum); (2) Roots and Tubers (yam, cassava, cocoyam and sweet potato); (3) Fruits (orange, pawpaw, banana, mangoes, watermelon, apples, avocado and pineapples); (4) Vegetables (Amaranths, onions, tomatoes and okra); (5) Meat and Poultry (chicken, beef, goat or sheep and bush meat, duck); (6) Eggs; (7) Fish (fresh fish, smoked fish, frozen fish, dried fish); (8) Pulses, Legumes and Nuts (cowpea, groundnut, cashew nut); (9) Milk and Milk products (fresh milk, cheese, milk powder, tinned milk); (10) Oil (groundnut oil, red palm oil, coconut oil, butter/margarine, sheabutter, animal fat); (11) Sugar (jam. honey); (12) Condiments (pepper, salt and spices) (FAO, 2007). These food groups were used to identify food intake quality of the households. Households that consumed a given category of food were given a value of 1 and 0 in the food categories that they do not consume.

The data used for this study comprised variety of foods and drinks from twelve food groups consumed by the households as a whole during the previous 24 hours. Every food item in the meals was coded. Dietary diversity was measured by summing the number of foods or food groups consumed over a reference period. The HDDS which ranged between 0-12 was used to measure household's dietary diversity and also ranked accordingly into high dietary diversity or food secure $(6-12=1)$ and low dietary diversity or food insecure $(<6=0)$ (FAO, 2008).

Instrumental Variable (IV) probit model was used to assess bicausality between human capital and food insecurity status among households in rural Nigeria. The IV probit is specified as in Eq. 1.

$Y_{I}=\alpha_{i}+\beta X_{i}+\mu_{i}$

Where: $\mathrm{Y}$ is dependent binary variable (food insecurity status $=1$ and 0 , otherwise); $\beta$ is $K X_{l}$ vector; $\mathrm{X}$ is $n X K$ matrix of covariates; $\mu$ is Error term.

Probit model can be biased because of endogeneity. In essence the correlation between the regressor and the error term is not zero $(\mathrm{E}(\mathrm{X}, \mathrm{U}) \neq 0)$, so the result of the estimation is inconsistent. So as to overcome this, instrumental variables were applied. Therefore, the model was written in it reduced form (Eq. 2, Eq. 3).

$Y_{1 i}^{*}=\beta Y_{21}+Y X_{1 i}+\mu_{i}$

$Y_{21}=X_{1 i} \pi_{1}+Z_{2 i} \pi_{2}+V_{i}$

Where:

$Y_{1 i}^{*}$ denotes the dependent variable for the ith observation (it answers the question if the household is food insecure or not);

$Y_{z i}$ denotes a vector of endogenous variable; $\mathrm{X}_{\mathrm{i}}$ exogenous variable which comprises; $\mathrm{X}_{1}$ Human capital index; $\mathrm{X}_{2}$ Household size; $\mathrm{X}_{3}$ Membership of association (yes $=1$, 0 if otherwise); $\mathrm{X}_{4}$ Farm size (Acres); $\mathrm{X}_{5}$ Gender (male $=1,0$ if otherwise); $\mathrm{X}_{6}$ Marital status ( married $=1,0$ if otherwise); $\mathrm{X}_{7}$ Per capita income ( $\left.\mathrm{N}\right) ; \mathrm{X}_{8}$ Occupation (Agriculture $=1,0$ if otherwise); $X_{9}$ Access to credit (yes $=1,0$ if otherwise); $\mathrm{X}_{10}$ Access to extension (Yes 1, 0 if otherwise); $\mathrm{X}_{11}$ Land ownership; $\mathrm{X}_{12}$ North Central; $\mathrm{X}_{13}$ North East; $X_{14}$ North West; $X_{15}$ South East; $X_{16}$ South South; $\mathrm{X}_{17}$ South West (Base).

\section{RESULTS AND DISCUSSION}

Food insecurity profile across household's socioeconomic characteristics

Food insecurity which is our dependent variable was determined using Dietary Diversity Score (DDS). Agada and Igbokwe (2015) defined dietary diversity as the number of different foods or food groups consumed by the household over a reference period not regarding the frequency of consumption. It is an outcome measure of food security at the individual or household level. In the present study dietary diversity refers to the number of food groups consumed at household level over a 24-hour 
period. About 83.02 percent of the respondents had low dietary diversity, while 16.98 percent had high DDS (food secure) (Table 1). This implies that majority of the respondents were food insecure (low DDS).

Households with elderly heads (> 75 years) had the highest proportion of households with low (2.45 percent) and high (2.87percent) DDS groups while those between $31-45$ years were the highest in both groups (37.77and 35.41 percent, respectively) (Table 1). This implies that household heads between 31 - 45 years age group had the highest dietary diversity and were more likely to have more than six (6) combinations of food categories compared to others. The highest proportion of food insecure ( 84.44 percent) and food secure (87.56 percent) households were the male-headed. However, a higher percentage of both male and female-headed households were food insecure (low DDS).

Further, in the low dietary diversity category, 74.46 percent and 25.54 percent of the married and unmarried households respectively had low diversity, while 74.16 percent of the married household heads had high diversity and 25.84 percent of the unmarried household heads also had high diversity. This implied that the unmarried household heads had low diversity compared to the married household heads. This is consistent with the findings of Obayelu and Awoyemi (2010); Grobler (2015) that households with unmarried heads were less food insecure than their married counterparts. The least proportion (17.51 percent) of households with low DDS were large ( $>10$ members) while those with 7 to 10 members had the highest proportion (37.57 percent). Conversely, the least (17.22 percent) proportion food secure (high DDS) had less than four members while those with 7 to 10 members had the highest (43.06 percent). This suggested that household that had 7 to 10 members were likely to be more diverse in their food category compared to other household sizes. A larger proportion of the household heads in both low and high DDS categories had no formal education.

A larger percentage of the rural household heads were primarily farmers representing 86.79 percent and 89.47 percent of food insecure and food secure household, respectively (Table 2). This invariably revealed food security paradox in rural Nigeria. Although most rural households were agrarian, they were food insecure. A majority ( 88.95 percent) of the rural households had no access to extension services representing 89.14 percent and 88.04 percent of households in both low and high DDS, respectively. Similarly, a majority (81.88 percent) of the rural households had no access to credit representing 83.86 percent and 72.52 percent of households in both low and high DDS, respectively. This indicated that most of the rural households had no access to productive assets like extension services and credit which is responsible for low level of investment and output and consequently low economic access to diverse food items.

Table 1: Food security profile by demographic characteristics of household heads

\begin{tabular}{|c|c|c|c|}
\hline \multirow[t]{2}{*}{ Demographic characteristics } & \multicolumn{3}{|c|}{ Dietary Diversity Categories } \\
\hline & Low $(\mathrm{N}=1022)$ & $\operatorname{High}(\mathrm{N}=209)$ & Total $(\mathrm{N}=1231)$ \\
\hline \multicolumn{4}{|c|}{ Age of household head (in years) } \\
\hline$<30$ & $43(4.21)$ & $17(8.13)$ & $60(4.87)$ \\
\hline $31-45$ & $386(37.77)$ & $74(35.41)$ & $460(37.37)$ \\
\hline $46-60$ & $372(36.40)$ & $70(33.49)$ & $442(35.91)$ \\
\hline $60-75$ & $196(19.18)$ & $42(20.10)$ & $238(19.33)$ \\
\hline$>75$ & $25(2.45)$ & $6(2.87)$ & $31(2.52)$ \\
\hline \multicolumn{4}{|l|}{ Gender } \\
\hline Male & $863(84.44)$ & $183(87.56)$ & $1046(84.97)$ \\
\hline Female & $159(15.56)$ & $26(12.44)$ & $185(15.03)$ \\
\hline \multicolumn{4}{|l|}{ Marital status } \\
\hline Married & $761(74.46)$ & $155(74.16)$ & $916(74.41)$ \\
\hline Unmarried & $261(25.54)$ & $111(25.84)$ & $315(25.59)$ \\
\hline \multicolumn{4}{|l|}{ Household size } \\
\hline $1-3$ & $195(19.08)$ & $36(17.22)$ & 231(18.77) \\
\hline $3-6$ & $264(25.83)$ & $40(19.14)$ & $304(24.7)$ \\
\hline $7-10$ & $384(37.57)$ & $90(43.06)$ & $474(38.51)$ \\
\hline$>10$ & $179(17.51)$ & $43(20.57)$ & $222(18.03)$ \\
\hline \multicolumn{4}{|c|}{ Level of formal education of household head } \\
\hline No formal & $407(39.82)$ & $75(35.89)$ & $482(39.16)$ \\
\hline Primary & $308(30.14)$ & $54(25.84)$ & $362(29.41)$ \\
\hline Secondary & 205() & 45() & 250() \\
\hline Tertiary & 102 & 35 & 137 \\
\hline
\end{tabular}


Table 2: Food security profile by economic characteristics of household heads

\begin{tabular}{llll}
\hline Economic variables & \multicolumn{2}{c}{ Dietary Diversity Categories } & \\
& Low $(\mathrm{N}=1022)$ & High $(\mathrm{N}=209)$ & Total $(\mathrm{N}=1231)$ \\
\hline Occupation & & & \\
Agriculture & $887(86.79)$ & $187(89.47)$ & $1074(87.25)$ \\
Non-agriculture & $135(13.21)$ & $22(10.53)$ & $157(12.57)$ \\
Access to extension & & & \\
No & $911(89.14)$ & $184(88.04)$ & $1095(88.95)$ \\
Yes & $111(10.86)$ & $25(11.96)$ & $136(11.05)$ \\
Access to credit & & & \\
No & $857(83.86)$ & $151(72.25)$ & $1008(81.88)$ \\
Yes & $165(16.14)$ & $58(27.75)$ & $223(18.12)$ \\
Land ow nership & & & \\
No & $260(25.44)$ & $44(21.05)$ & $304(24.70)$ \\
Yes & $762(74.56)$ & $165(78.95)$ & $927(75.30)$ \\
Farm size (in ha) & & & \\
$<1$ & $960(93.93)$ & $185(88.52)$ & $1145(93.01)$ \\
$1-5$ & $61(5.97)$ & $23(11.00)$ & $84(6.82)$ \\
$>6$ & $1(0.10)$ & $1(0.48)$ & $2(0.16)$ \\
Per capita annual income $(\mathrm{N})$ & & \\
$<20000$ & $450(44.03)$ & $97(46.41)$ & $547(44.44)$ \\
$20001-40000$ & $367(35.91)$ & $76(36.36)$ & $443(35.99)$ \\
$40001-60000$ & $40(3.91)$ & $6(2.87)$ & $46(3.74)$ \\
$60001-80000$ & $61(5.97)$ & $10(4.78)$ & $71(5.77)$ \\
$>80000(\$ 222.2)$ & $104(10.18)$ & $20(9.57)$ & $124(10.07)$ \\
\hline
\end{tabular}

About three-quarters of household with low DDS owned land while 78.95 percent of those with high DDS were land owners (Table 2); implying that those households that owned land were more likely to be slightly food secure than landless household heads that do not own any land. This may probably be due to the fact that they can produce different varieties of crops on their land and this in turn gave them access to an array of food crops they could grow and consume daily. Further, the majority (93.01 percent) of households were smallholder farmers representing 93.93 percent and 88.52 percent of households with low and high DDS, respectively. A larger percentage of the rural households were living in chronic poverty (less than $\$ 1 /$ day $=<\mathrm{N} 80,000 /$ day). Consequently, smallholder agriculture characterised with small land holdings with no land property right, low per capita income, lack of access to credit and extension services explains high level of low dietary diversity scores in rural Nigeria.

Further, the South-south geopolitical zone had the highest contribution to low dietary diversity (Table 3). This could be explained be low level of farming and fishing livelihood activities owing to oil spillage in the South-south. Low level of livelihood is expected to erode household welfare and dietary diversity. Although the incidence of low dietary diversity was higher than high dietary diversity in all the geopolitical zones, Northwest had the highest contribution to high dietary diversity. The Human Capital Index (HCI) was categorised into three groups. This comprised low $(<0.33)$, medium $(0.33<\mathrm{HCI}<0.66)$ and high $(>0.66)$ human capital categories. While 22.97 percent of the households that had low human capital, 39.23 percent of the households that had medium human capital and 37.80 of the household head that had high human capital had high dietary diversity. This implies that household heads that had medium level of human capital the high dietary diversity compared to household with other categories of human capital.

Table 4 presented the results of Instrumental Variable (IV) probit regression analysis on the test of endogeneity between human capital and food insecurity among households in rural Nigeria. The positive sign of a coefficient implies that an increase in the value of an independent variable increases the probability of a household being food insecure (decreasing food security) given other factors. Conversely, a negative sign of the independent variable means that an increase in the value of an independent variable reduces the probability of the household being food insecure (increasing food security), given other factors.

Human capital index had a negative relationship with food insecurity. This index was constructed using the Principal Component Analysis (PCA). The analysis of the result showed that an increase in the level of human capital brought about a decrease in food insecurity. This implies that household heads with a level of human capital were less likely to be food insecure thereby increasing the probability of a household being food secure than household heads that lacked human capital. The marginal effect revealed that a unit increase in the level of human capital brought about a decrease in food insecurity by 1.03 units.

Gender of the household head had a negative relationship with food insecurity implying that maleheaded households were less likely to be food insecure than female-headed households. This may probably be because in most rural areas, males have more access to productive assets than their female counterparts. 
Table 3: Food security profile by geo-political zones and human capital

\begin{tabular}{llll}
\hline Variables & \multicolumn{2}{l}{ Dietary Diversity categories } & \\
& Low $(\mathrm{N}=1022)$ & High $(\mathrm{N}=209)$ & Total $(\mathrm{N}=1231)$ \\
\hline Zones & & & \\
North Central & $166(16.24)$ & $27(12.92)$ & $193(15.68)$ \\
North East & $137(13.41)$ & $42(20.10)$ & $179(14.54)$ \\
North West & $183(17.91)$ & $48(22.97)$ & $231(18.77)$ \\
South East & $197(19.28)$ & $32(15.31)$ & $229(18.60)$ \\
South South & $215(21.04)$ & $39(18.66)$ & $254(20.63)$ \\
South West & $124(12.13)$ & $21(10.05)$ & $145(11.78)$ \\
Human capital & & & \\
Low & $301(29.45)$ & $48(22.97)$ & $349(28.35)$ \\
Medium & $362(35.42)$ & $82(39.23)$ & $444(36.07)$ \\
High & $359(35.13)$ & $79(37.80)$ & $438(35.58)$ \\
\hline
\end{tabular}

Table 4: Assessment bi-causality between human capital and food security status among households in Rural Nigeria

\begin{tabular}{|c|c|c|}
\hline Food security & Coefficient & Marginal effect \\
\hline \multirow{2}{*}{ Human capital index } & $-1.0336 * * *$ & $-1.0336 * * *$ \\
\hline & $-(10.17)$ & $-(10.17)$ \\
\hline \multirow[t]{2}{*}{ Gender } & $-0.3868 * *$ & $-0.3867 * *$ \\
\hline & $-(1.70)$ & $-(1.70)$ \\
\hline \multirow[t]{2}{*}{ Marital status } & 0.0207 & 0.0207 \\
\hline & $(0.79)$ & $(0.79)$ \\
\hline \multirow[t]{2}{*}{ Household size } & $-0.0935^{* * *}$ & $-0.0935 * * *$ \\
\hline & $-(6.24)$ & $-(6.24)$ \\
\hline \multirow[t]{2}{*}{ Occupation } & -0.0601 & -0.0601 \\
\hline & $-(0.27)$ & $-(0.27)$ \\
\hline \multirow[t]{2}{*}{ Access to extension } & $-0.3570 * *$ & $-0.3570 * *$ \\
\hline & $-(2.03)$ & $-(2.03)$ \\
\hline \multirow[t]{2}{*}{ Access to credit } & -0.0758 & -0.0758 \\
\hline & $-(0.32)$ & $-(0.32)$ \\
\hline \multirow[t]{2}{*}{ Membership of association } & $-0.7868 * * *$ & $-0.7867 * * *$ \\
\hline & $-(3.99)$ & $-(3.99)$ \\
\hline \multirow[t]{2}{*}{ Per capita income } & $-2.32 \mathrm{e}-07$ & $4.73 e-07$ \\
\hline & $-(0.47)$ & $(1.11)$ \\
\hline \multirow[t]{2}{*}{ Land ow nership } & $-0.3039 * *$ & $-0.3038 * *$ \\
\hline & $-(1.78)$ & $-(1.78)$ \\
\hline \multirow[t]{2}{*}{ Farm size } & $6.42 \mathrm{e}-06$ & $6.42 \mathrm{e}-06$ \\
\hline & $(0.64)$ & $(0.64)$ \\
\hline \multirow[t]{2}{*}{ North Central } & $0.3893 * * *$ & $0.3891 * * *$ \\
\hline & $(2.56)$ & $(2.56)$ \\
\hline \multirow[t]{2}{*}{ North East } & $0.5171 * * *$ & $0.5171 * * *$ \\
\hline & $(2.14)$ & $(2.14)$ \\
\hline \multirow[t]{2}{*}{ North West } & $0.5003 * *$ & $0.5003 * *$ \\
\hline & $(2.12)$ & $(2.12)$ \\
\hline \multirow[t]{2}{*}{ South East } & -0.0485 & -0.0485 \\
\hline & $-(0.33)$ & $-(0.33)$ \\
\hline \multirow[t]{2}{*}{ South South } & $0.3288 * *$ & $0.3288 * *$ \\
\hline & $(2.30)$ & $(2.30)$ \\
\hline \multirow[t]{2}{*}{ Constant } & 2.3659 & \\
\hline & $(4.72)$ & \\
\hline \multicolumn{3}{|l|}{ Wald chi2 $2(11)=984.37$} \\
\hline \multicolumn{3}{|l|}{ Prob $>$ chi $2=0.0000$} \\
\hline \multicolumn{3}{|l|}{ Log likelihood $=-1779.3724$} \\
\hline \multicolumn{3}{|l|}{ Number of observation $=978$} \\
\hline
\end{tabular}


This will make food to be more available to the household and in essence reduce food insecurity. In addition, larger the household were less probable to being food insecure than those with fewer members. This is because among rural households, an increase in household size will lead to an increase in amount of labour available for farming activities. This will eventually lead to an increase in food production and thereby help in reducing food insecurity among the households. The probability of being food insecure will decrease by 0.09 unit with an additional family member in adult equivalent. This result is contrary to the findings of Frehiwot (2007) and Sekhampu (2017) that increase in household size exacerbates food insecurity.

Access to extension also had a negative relationship with household food insecurity suggesting that household heads with extension contact were less likely to be food insecure than those without extension contact. Households whose heads belonged to one or more association were less likely to be food insecure than those without any association. This can be closely linked to the beneficial effects of their membership, in terms of production and other welfare enhancing services that were offered by the societies and organizations. It could also be that members of the households in cooperative were given the opportunity to take loans in order to manage their agricultural activities. In addition, land ownership had a negative relationship with household food insecurity indicating that household heads that owned one or more lands were less likely to be food insecure. This may probably be due to the fact that lands in the rural areas were majorly used for agricultural activities. This will avail the households to engage more in farming activities that involves food production. Finally, households residing in North Central, North East North West zone, and South South geopolitical zones had positive relationship with the household food insecurity status suggesting that households residing in these zones were more likely to be food insecure relative to those in South West. The northern regions are known for high prevalence of poverty (Obayelu and Awoyemi, 2010) are therefore susceptible to high level of food insecurity.

\section{Weak instrument robust test for instrumental variable ((Riv test) probit regression.}

The Riv test is a set of test carried out to test for the strength or weakness of the instrumental variables in IV probit regression. The Anderson Rubin (AR) statistics by (Anderson and Rubin, 1949) was used to test for the strength of the instrumental variables. The result showed that the null hypothesis was rejected at 5 percent indicating that the ins trumental variable (religion) was not weak (Table 5). The Wald test is a summary of all the test statistics and the result showed that there was no bicausality between human capital and food insecurity.

Table 5: Riv test of instrumental variables (IV) Probit regression

\begin{tabular}{lll}
\hline Test & Statistic & P-value \\
\hline AR & chi2 $(1)=1.54$ & Prob $>$ chi $2=0.2145$ \\
Wald & Chi2 $(1)=103.51$ & Prob $>$ chi $2=0.0000$ \\
\hline
\end{tabular}

\section{CONCLUSIONS}

The food security profile showed that household heads that had medium level of human capital were more food secured. Household size, membership of association and access to extension significantly influence human capital. The result revealed that there was no endogeneity between human capital and food insecurity. The study also found out that human capital index which comprises age, age squared, education, number of inactive days and body mass index though not significant, had a negative relationship with food insecurity such that as human capital increases, food insecurity decreases. Based on the findings from the study that investment in human capital (health, education, nutrition and skills) helps in reducing food insecurity. Likewise access to credit and extension services give the rural people the opportunity of involving in activities that aids in building their human capital base thereby reducing food insecurity. It is therefore suggested that governments at all levels should intensify programmes on human capital development that will improve human capital base in rural Nigeria especially in the Northern zones where food insecurity were more endemic. Furthermore, market-based intervention policies such as access to credit facilities, that facilitate households' livelihood activities and access at all times to healthy foods of their choice, should be given priority. This will give the household opportunity to benefit from greater varieties of food items offered by the market. Government should provide comprehensive extension training programmes that will increase productivity of the rural households and hence reduce food insecurity among the households.

\section{REFERENCES}

ADEPOJU, A. O. and ADEJARE, K. A. (2013). Food insecurity status of rural households during the postplanting season in Nigeria. Journal of Agriculture and Sustainability, 4(1): 16-35.

AGADA, M. O. and IGBOKWE, E. M. (2015). Dietary Diversity of Rural Households in North Central Nigeria. European Journal of Nutrition and Food Safety 5(3): 150155. DOI: $10.9734 / \mathrm{EJNFS} / 2015 / 14875$

AGBOLA, P. O (2013). Factors influencing food insecurity among small farmers in Nigeria. African Journal of Agricultural Research, 9: 2104-2110. DOI: 10.5897/AJAR09.710

AJANI, S. R. (2010). An assessment of dietary diversity in six Nigerian States. Afr. J. Biomed. Res, 13: 161 -167. AMINU, M. and NYAKO, B. S. (2013). The relationship between educational attainment and food security in Nigeria. Faculty of the Graduate School of Arts and Sciences of Georgetown University Washington, DC

ANDERSON, T. W. and RUBIN, H. (1949). Estimation of the parameters of a single equation in a complete system of stochastic equations. Annals of Mathematical Statistics 20, 46-63

AYANTOYE, K., YUSUF, S. A. OMONONA, B.T. and AMAO, J. O. (2011). Food insecurity dynamics and its correlates among rural households in South Western 
Nigeria. International Journal of Agricultural Economics and Rural Development 4(1): 43-55.

CONCEIÇÃO, P., FUENTES-NIEVA, R., LEO HORNPHATHANOTHAI, L. and NGORORANO, A. (2011). Food Security and Human Development in Africa: Strategic Considerations and Directions for Further Research. African Development Review, Vol. 23, Issue2. Special Issue: Special Issue on the 2010 African Economic Conference on "Setting the Agenda for Africa's Economic Recovery and Long-term Growth". Pages 237-246. DOI: https://doi.org/10.1111/j.1467-8268.2011.00283.x

FAFCHAMPS, M. and QUISUMBING, A. R. (1998). Human capital, productivity, and labor allocation in rural Pakistan. Food Consumption and Nutrition Division, International Food Policy Research Institute, $2033 \mathrm{~K}$ Street, N.W. Washington, D.C. 20006 U.S.A. (202) 8625600.

FOOD AND AGRICULTURE ORGANIZATION (FAO) (2008). Food Security Information for Action: Vulnerability Indicators. Food and Agriculture Organization of the United Nations: Rome, Italy.

FOOD AND AGRICULTURE ORGANIZATION (FAO) (2015). The State of Food Insecurity in the World 2015. Food and Agriculture Organization of the United Nations, Rome

FOOD AND AGRICULTURE ORGANIZATION (FAO) (2007). Guidelines for measuring household and individual dietary diversity', Nutrition and Consumer Protection Division with support from the EC/FAO Food Security Information for Action Programme and the Food and Nutrition Technical Assistance (FANTA) Project, Rome, Italy.

FREHIWOT, F.S. (2007). Food Insecurity and its Determinants in Rural Households in Amhara Region. Addis Ababa University.

GROBLER, W. C. J. (2015). Socio Economic Determinants of Household Dietary Diversity in a Low Income Neighbourhood in South Africa. Proceedings of 30th International Business Research Conference 20 - 22 April 2015, Flora Grand Hotel, Dubai, UAE, ISBN: 9781-922069 74-0.

HABICHT, J. and PELLETIER, J. (1990). The importance of context in choosing nutritional indicators. $J$ Nutr 120S:1519-1524. DOI: 10.1093/jn/120.suppl_11.1519

MANYONG, V. M., IKPI, A., OLAYEMI, J. K., YUSUF, S. A., OMONONA, B. T., OKORUWA, V. and IDACHABA, F. S. (2005). Agriculture in Nigeria: Identifying Opportunities for Increased Commercialization and Investment. IITA, Ibadan: IITA. MWANIKI, A. (2005). Achieving Food Security in Africa: Challenges and Issue. Cornell University Discussion Paper.

NATIONAL BUREAU OF STATISTICS (NBS) (2016). General Households Survey 2015 - 2016. Panel Data for Nigeria. Abuja: NBS.

OBAMIRO, E., DOPPLER, W. and KORMAWA, M. (2003). Pillars of Food Security in Rural Areas in Nigeria. Food Africa, Internet forum. 31st March - 11 April, 2003. OBAYELU, O. A. and AWOYEMI, T. T. (2010). Spatial dimension of poverty in rural Nigeria. Journal of
Development and Agricultural Economics, Vol. 2(6) June 2010: 231-244

OFFIONG, U. U., NWEZE, N. J. and ARENE, C. J. (2016). Food insecurity vulnerability status of farm households in Niger-Delta, Nigeria. International Journal of Food and Agricultural Economics, 4(1): 109-123 109. OGUNDARI, K. O. (2017). Categorizing households into different food security states in Nigeria: the socioeconomic and demographic determinants. Agricultural and Food Economics (2017) 5(8). DOI: https://doi.org/10.1186/s40100-017-0076-y

ONI, O. A., SALMAN, K. K. and IDOWU, B. O. (2011): Social Capital Dimensions and Food Security among Farming Households in Ogun State, Nigeria. Journal of American Science 7(8): 776-783.

OUÉDRAOGO, S. (2005). Intensification de l'agriculture dans le Plateau Central du Burkina Faso: une Analyse des possibilités à partir des nouvelles technologies. (Doctoral dissertation). Rijksuniversiteit Groningen, pp. 336.

SANCHEZ, P. and SACHS, J. (2004). Une révolution verte pour l'Afrique. le Monde, du 10 août 2004.

SCHULTZ, T. (1961). Investment in Human Capital. American Economic Review 51(1):1-17. https://www.jstor.org/stable/1818907

SEKHAMPU, T. J. (2017). Association of food security and household demographics in a South African township. International Journal of Social Sciences and Humanity Studies, 9(2):157-170

UNITED NATIONS (2009). The Millennium Development Goals Report, 2009.

WIGGINS, S. and KEATS, S. (2009). Current state of food security in Africa and the Africa - EU partnership on the Millennium Development Goals. Paper for Second Joint Experts Group Meeting, Africa-EU MDGs Partnership, Sub Group on Priority Action 2: Accelerate the Food Security targets of the MDGs, 24 March 2009, Pretoria.

WORLD BANK (WB) (2001). World Bank Development report. 2000/2001. Washington D.C. The World Bank. www.worldbank.org. Website visited on 22/04/05

WORLD BANK (WB) (2018). Rural population (\% of total population). Data.

https://data.worldbank.org/indicator/SP.RUR.TOTL.ZS 